\title{
The Photocatalytic Reduction of Hexavalent Chromium by Controllable Mesoporous Anatase $\mathrm{TiO}_{2}$ Nanoparticles
}

\author{
Vorrada Loryuenyong, ${ }^{1,2}$ Natnapin Jarunsak, ${ }^{1}$ \\ Thirawich Chuangchai, ${ }^{1}$ and Achanai Buasri ${ }^{1,2}$ \\ ${ }^{1}$ Department of Materials Science and Engineering, Faculty of Engineering and Industrial Technology, \\ Silpakorn University, Nakhon Pathom 73000, Bangkok 10330, Thailand \\ ${ }^{2}$ National Center of Excellence for Petroleum, Petrochemicals and Advanced Materials, Bangkok 10330, Thailand \\ Correspondence should be addressed to Vorrada Loryuenyong; vorrada@gmail.com
}

Received 28 May 2013; Accepted 25 October 2013; Published 20 January 2014

Academic Editor: Ho Chang

Copyright (C) 2014 Vorrada Loryuenyong et al. This is an open access article distributed under the Creative Commons Attribution License, which permits unrestricted use, distribution, and reproduction in any medium, provided the original work is properly cited.

Titania $\left(\mathrm{TiO}_{2}\right.$ ) nanoparticles with periodical mesopore size (up to $150 \AA$ ) have successfully been synthesized by sol-gel template method, using titanium(IV) tetraisopropoxide as a starting precursor and isopropanol as a solvent. Different quantities of activated carbon $(0 \%, 5 \%$, and $10 \%$ by weight) were used as templates to control the porosity and particle size of titania nanoparticles. The templates were completely removed during the calcination in air at $500^{\circ} \mathrm{C}$ for $3 \mathrm{hr}$. The results showed that the specific surface area of titania is increased with increasing activated carbon content. The optical bandgap of synthesized titania exhibits a blue shift by $0.3-0.6 \mathrm{eV}$ when compared to the reported value for the bulk anatase and rutile phases. The photocatalytic activity of porous titania is determined with its reduction efficiency of hexavalent chromium $\left(\mathrm{Cr}^{6+}\right)$. The reduction efficiency is optimized under ultraviolet illumination.

\section{Introduction}

In general, chromium has two stable oxidation states, that is, $\mathrm{Cr}(\mathrm{VI})$ and $\mathrm{Cr}(\mathrm{III})$. The toxicity is mainly caused by hexavalent chromium, $\mathrm{Cr}(\mathrm{VI})$, which is virtually found in wastewater from industrial processes such as leather tanning, paint making, electroplating, and chromate production. This oxidation state has been classified as a carcinogen and mutagen not only to humans but also to other creatures. In many countries, as a consequence, the wastewater must be treated until the limit of $\mathrm{Cr}(\mathrm{VI})$ is below $0.05 \mathrm{mg} / \mathrm{L}$ before releasing to the water source [1]. One solution method is to convert it into $\mathrm{Cr}(\mathrm{III})$, which is considered as a nontoxic and essential trace metal in human nutrition. By chemical process, $\mathrm{Cr}(\mathrm{VI})$ is precipitated into $\mathrm{Cr}(\mathrm{III})$ as $\mathrm{Cr}(\mathrm{OH})_{3}$ in neutral or alkaline solutions and removed as a solid waste $[2,3]$. However, this process requires reducing agents such as ferrous sulfate, sodium hydrogen sulfite, sodium pyrosulfite, hydrazine hydrate, and sulfur dioxide, which are expensive and dangerous with human skin and to release other unwanted chemicals [1].

Recently, there are many research works related to the use of semiconducting materials such as $\mathrm{TiO}_{2}$ and $\mathrm{ZnO}$ as photocatalysts for various applications. This has many benefits including low cost, high efficiency, reusable performance, cleanliness, natural safety, and nontoxicity. The photocatalytic mechanism begins when a semiconducting material absorbs light with energy larger than its bandgap. As a consequence, electrons from the valence band would be excited to the conduction band, leaving holes behind. These electron-hole pairs could react with oxygen and water in air to produce free radicals such as hydroxyl radical, hydrogen peroxide, and superoxide anions. Such free radicals have an ability to destroy the structure of the bacteria, hold back the virus, and react with organic compound to become carbon dioxide and water. In addition, They can react with toxic gas and carcinogen such as acetaldehyde, benzene, and formaldehyde. 
Due to an oxygen defect, titania $\left(\mathrm{TiO}_{2}\right)$ exists naturally as an n-type semiconducting photocatalyst with an intrinsic bandgap of 3.0-3.2 eV. Among four major phases, anatase, rutile, brookite, and titania- $\mathrm{B}$, anatase is generally the most photocatalytically active, owing to its wide bandgap, high specific surface area, and low recombination rates of electronhole pairs [4-6]. On the other hand, rutile is a hightemperature stable phase and has high refractive index and weatherability. Nevertheless, many researchers have reported that the mixed phase of anatase and rutile has higher photocatalytic activity and better optical properties than pure anatase phase [7]. Despite phase, other important properties including well-controlled porosity and crystallinity are also desirable in photocatalytic applications [8].

In this research, activated carbon was used as a template for producing uniform mesoporous $\mathrm{TiO}_{2}$ with anatase phase by sol-gel method. The physical properties of synthesized $\mathrm{TiO}_{2}$ were studied. The reduction efficiency of $\mathrm{Cr}(\mathrm{VI})$ performance by synthesized $\mathrm{TiO}_{2}$ as a photocatalyst was determined. The effect of wavelength lighting source with photocatalytic performance was also discussed.

\section{Materials and Methods}

2.1. Synthesis of $\mathrm{TiO}_{2}$ Nanoparticles. The synthesis was carried out as reported in the literature $[6,7]$. All reagents including titanium(IV) tetraisopropoxide (TIP) (Sigma-Aldrich, USA) as a $\mathrm{Ti}$ precursor, 37\% $\mathrm{HCl}$ (Merck KGaA, Germany) as a sol-gel catalyst, isopropanol (Merck KGaA, Germany) as a solvent, and activated carbon (CGO-200, C. Gigantic Carbon) as a template were used without further purification.

$5.5 \mathrm{~mL}$ TIP was dissolved in $71.8 \mathrm{~mL}$ isopropanol, and then, if applicable, $0.073 \mathrm{~g}$ (5\% activated carbon by weight of synthesized $\mathrm{TiO}_{2}$ ) or $0.145 \mathrm{~g}$ activated carbon $(10 \%$ by weight of synthesized $\mathrm{TiO}_{2}$ ) was added to the solution. The mixed solution of $19 \mathrm{~mL}$ water and $1.68 \mathrm{~mL} \mathrm{HCl}$ was then added dropwise to titania-activated carbon suspensions under vigorous stirring at room temperature. The mixture was further stirred for $3 \mathrm{hr}$, and the obtained gel was centrifuged, washed to remove excess reactants and catalyst, and dried in the oven at $80^{\circ} \mathrm{C}$ for $24 \mathrm{hr}$. The dried samples were grinded and calcined at $500^{\circ} \mathrm{C}$ for $3 \mathrm{hr}$ at the heating rate of $5^{\circ} \mathrm{C} / \mathrm{min}$. The samples would be labelled as $0 \% \mathrm{AC}, 5 \% \mathrm{AC}$, and $10 \% \mathrm{AC}$ for $\mathrm{TiO}_{2}$ synthesized with $0 \%, 5 \%$, and $10 \%$ activated carbon, respectively.

2.2. Characterization. Thermogravimetric analysis (TGA) (TGA7, Perkin Elmer) was used to characterize the thermal stability of the samples by measuring the change in weight as a function of temperature. Fourier transform infrared spectroscopy (FTIR) (Vertex70, Bruker Optics) was used for studying the functional groups in the samples. X-ray diffraction (XRD) patterns were obtained on a Miniflex II, Rigaku diffractometer. Transmission electron microscope (TEM) (JEM-1230, JEOL) was employed to study the morphology of the synthesized samples. The specific surface area, the pore size distribution, and the average pore size of samples were evaluated by nitrogen adsorption and desorption as a function of relative pressure, using Brunauer-Emmett-Teller

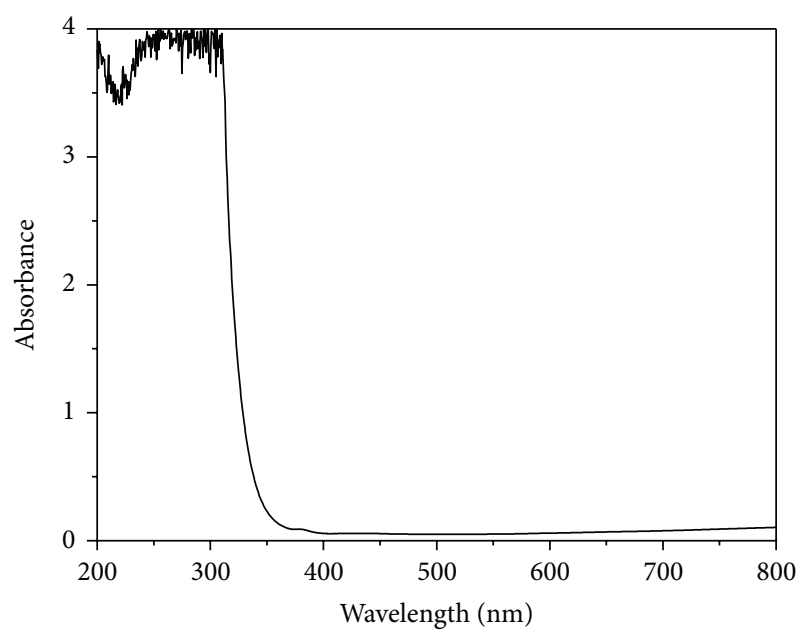

FIGURE 1: The absorbance spectrum of the filter.

(BET) and Barrett-Joyner-Halenda (BJH) methods. The \% absorbance of samples was analyzed by UV-Vis spectrophotometer (UV-1800, Shimazu).

2.3. Reduction of $\mathrm{Cr}(\mathrm{VI})$. In order to prepare $50 \mathrm{mg} / \mathrm{L}$ $\mathrm{K}_{2} \mathrm{Cr}_{2} \mathrm{O}_{7}$ aqueous solution, $50 \mathrm{mg} \mathrm{K}_{2} \mathrm{Cr}_{2} \mathrm{O}_{7}$ was added to a $1000 \mathrm{~mL}$ volumetric flask, and then the deionized water was poured until the solution level reached the $1000 \mathrm{~mL}$ mark on the neck of the flask. $0.02 \mathrm{~g} \mathrm{TiO}_{2}(0 \%, 5 \%$, or $10 \% \mathrm{AC})$ was then added to $20 \mathrm{~mL} \mathrm{~K}_{2} \mathrm{Cr}_{2} \mathrm{O}_{7}$ solution in separated $50 \mathrm{~mL}$ beakers. The suspensions were maintained at $\mathrm{pH}=5$ and vigorously stirred for 5 minutes before being illuminated by a light source. The illumination was performed at 150 watts and at a distance of $11 \mathrm{~cm}$, measured from the tip of the lamp, using Newport's Oriel Solar simulator with actual spectral irradiance reported elsewhere $(150 \mathrm{~W}$ low cost solar simulator, Newport Corporation). The absorbance of illuminated suspension was measured every 10 minutes for a total of 120 minutes. The effects of UV light illumination were conducted by the use of filter with light absorbance spectrum shown in Figure 1.

\section{Results and Discussions}

Figure 2 shows TGA and DTA graphs of synthesized $\mathrm{TiO}_{2}$ nanoparticles before calcination. The graph illustrates a weight loss at $100^{\circ} \mathrm{C}$ due to the release of the humidity and organic compounds. The samples synthesized with $5 \%$ and $10 \%$ activated carbon template, however, show two clearly defined steps of weight loss. Additional weight loss at the second step occurs at $500^{\circ} \mathrm{C}$ due to the decomposition of activated carbon. After calcination, as shown in Figure 3, it is found that the weight loss at $500^{\circ} \mathrm{C}$ disappears, confirming that activated carbon template is completely decomposed.

Figure 4 shows FTIR spectra of synthesized $\mathrm{TiO}_{2}$ nanoparticles before calcination. It is observed that all of the graphs have 3 main peaks: (1) $\mathrm{O}-\mathrm{H}$ stretching at $3400 \mathrm{~cm}^{-1}$, (2) $\mathrm{O}-\mathrm{H}$ bending at $1635 \mathrm{~cm}^{-1}$, and (3) $\mathrm{Ti}-\mathrm{O}$ stretching at 
Table 1: Physical properties of $\mathrm{P} 25$ Aeroxide $\mathrm{TiO}_{2}$ and synthesized $\mathrm{TiO}_{2}$ nanoparticles.

\begin{tabular}{lcccc}
\hline Samples & $\begin{array}{c}\text { Specific surface area } \\
\left(\mathrm{m}^{2} / \mathrm{g}\right)\end{array}$ & $\begin{array}{c}\text { Pore diameter } \\
(\mathrm{nm})\end{array}$ & $\begin{array}{c}\text { Pore volume } \\
\left(\mathrm{cm}^{3} / \mathrm{g}\right)\end{array}$ & $\begin{array}{c}\text { XRD particle size } \\
(\AA)\end{array}$ \\
\hline $0 \% \mathrm{AC}$ & 69.28 & 11.25 & 0.19 & 132 \\
$5 \% \mathrm{AC}$ & 94.34 & 7.92 & 0.19 & 105 \\
$10 \% \mathrm{AC}$ & 82.46 & 10.21 & 0.21 & 111 \\
P25 & 61.00 & 67.3 & 1.03 & 180 \\
\hline
\end{tabular}

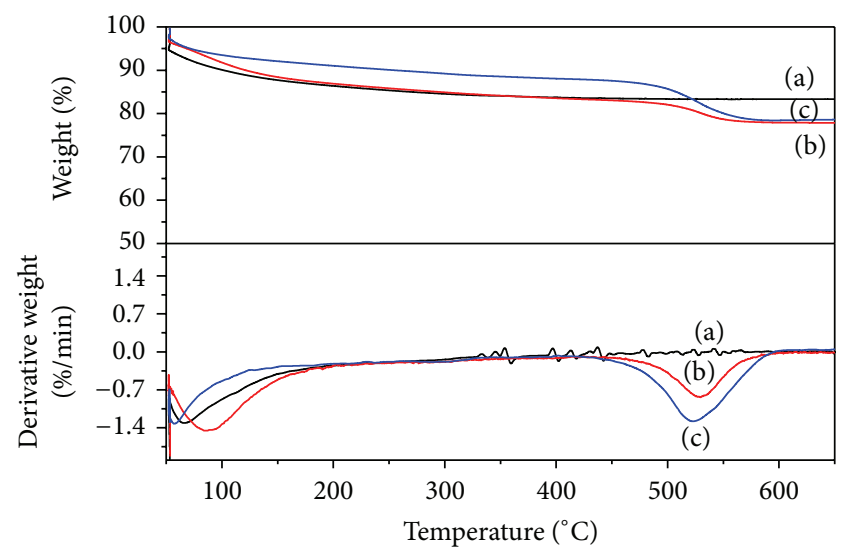

Figure 2: TGA-DTA of synthesized $\mathrm{TiO}_{2}$ nanoparticles using an activated carbon template in different quantities and with no calcination: (a) $0 \%$, (b) 5\%, and (c) $10 \%$.

$700-400 \mathrm{~cm}^{-1}$. After calcination, however, the intensity of peaks at $3400 \mathrm{~cm}^{-1}$ and $1635 \mathrm{~cm}^{-1}$ is decreased due to the condensation of Ti-OH followed by the formation of a $\mathrm{TiO}_{2}$ network structure (Figure 5). In addition, the intensity of the peak at $700-400 \mathrm{~cm}^{-1}$ is evidently increased due to the stretching vibration of $\mathrm{Ti}-\mathrm{O}-\mathrm{Ti}$ in anatase phase.

Figure 6 shows the X-ray diffraction (XRD) patterns of $\mathrm{TiO}_{2}$ nanoparticles. All the XRD peaks could be indexed as (101), (004), (200), (105), (211), (118), and (315) at 2-theta = $25,38,48,53,55,63$, and $75^{\circ}$, respectively, which corresponds to an anatase phase. The particle size of $\mathrm{TiO}_{2}$ was calculated with the Scherrer formula using the XRD peak of anatase (101) plane as shown in Table 1. Smaller particle size is observed with the use of activated carbon template. In comparison to P25 Aeroxide $\mathrm{TiO}_{2}$ which contains anatase and rutile phases, the results show that pure anatase $\mathrm{TiO}_{2}$ could be made via the hydration of titanium(IV) isopropoxide using a sol-gel technique and activated carbon template.

The morphologies of calcined $\mathrm{TiO}_{2}$ are shown in Figure 7. It is found that $\mathrm{TiO}_{2}$ nanoparticles are spherical in shape and do not agglomerate together. The particle size is similar to that predicted from XRD analysis. It could be predicted that the activated carbon as a template restrained the growth of $\mathrm{TiO}_{2}$ particles, consistent with that reported previously [7].

Figures 8 and 9 show the $\mathrm{N}_{2}$ adsorption/desorption isotherms and the corresponding $\mathrm{BJH}$ pore size distribution of titania nanoparticles, respectively. From the figure, it is observed that the isotherm of the synthesized $\mathrm{TiO}_{2}$ can be ascribed to type IV. A summary of BET results is illustrated

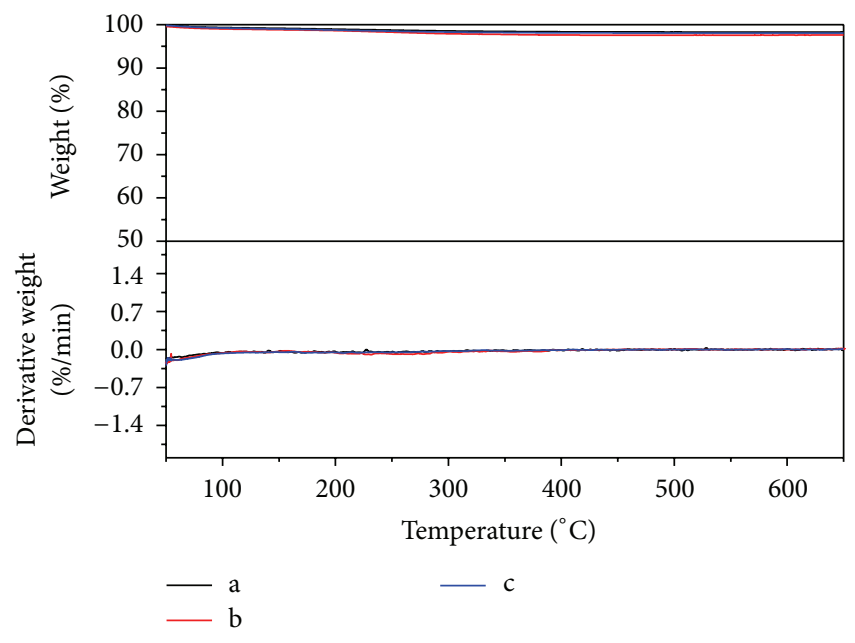

FIgURE 3: TGA-DTA of synthesized $\mathrm{TiO}_{2}$ nanoparticles using an activated carbon template in different quantities and with calcination at $500^{\circ} \mathrm{C}$ for $3 \mathrm{hr}$ : (a) $0 \%$, (b) $5 \%$, and (c) $10 \%$.

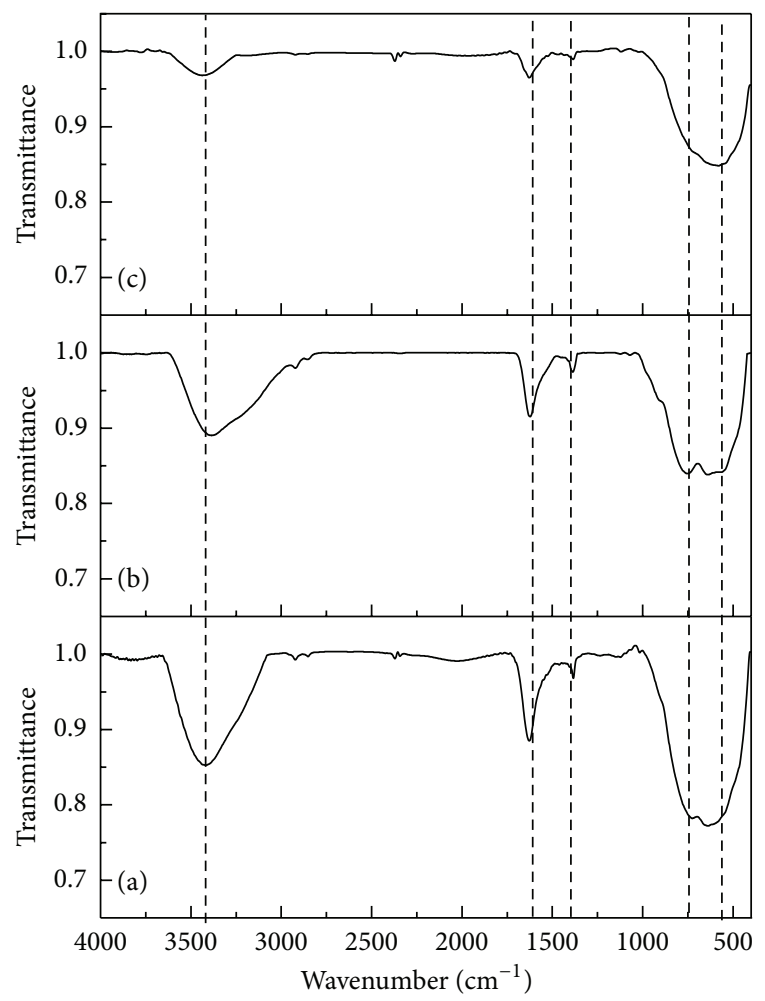

FIGURE 4: FTIR graphs of synthesized $\mathrm{TiO}_{2}$ nanoparticles using an activated carbon template in different quantities and with no calcination: (a) $0 \%$, (b) $5 \%$, and (c) $10 \%$. 


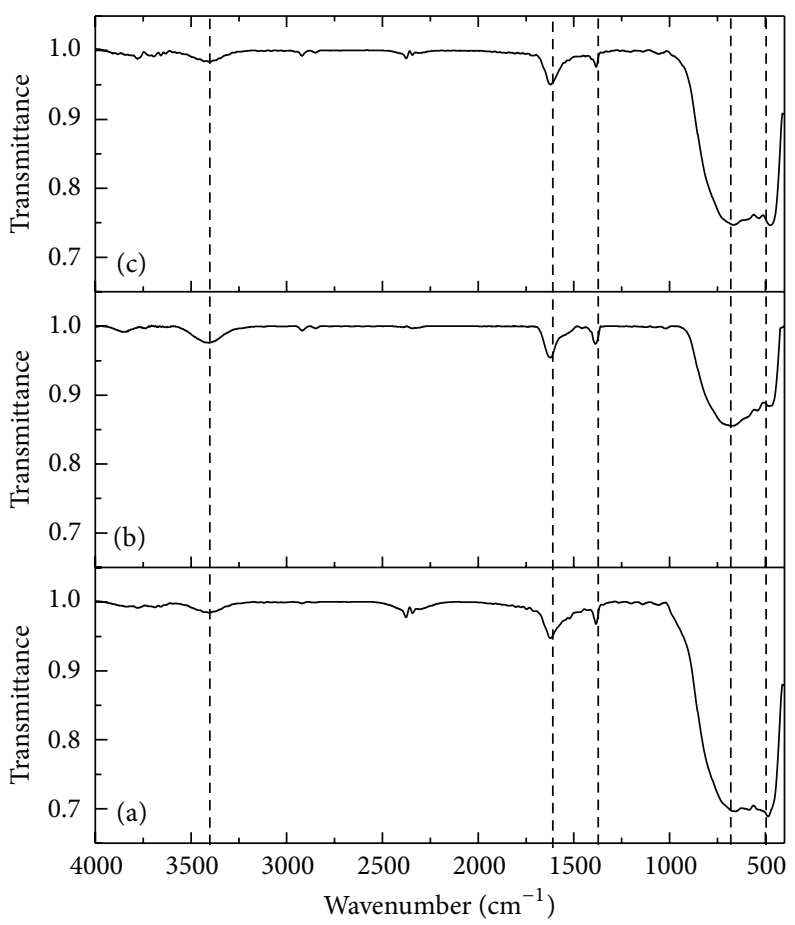

FIGURE 5: FTIR graphs of synthesized $\mathrm{TiO}_{2}$ nanoparticles using an activated carbon template in different quantities and with calcination at $500^{\circ} \mathrm{C}$ for $3 \mathrm{hr}$ : (a) $0 \%$, (b) $5 \%$, and (c) $10 \%$.

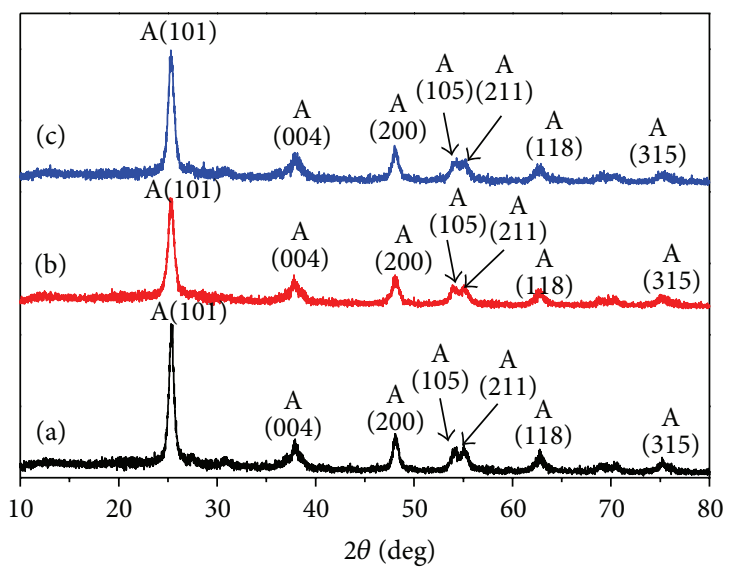

Figure 6: XRD pattern of synthesized $\mathrm{TiO}_{2}$ nanoparticles: (a) $0 \% \mathrm{AC}$, (b) $5 \% \mathrm{AC}$, and (c) $10 \% \mathrm{AC}$ (A: anatase).

in Table 1, in comparison with those of commercial P25 Aeroxide $\mathrm{TiO}_{2}$ nanoparticles. As shown, activated carbon templates are likely to increase the specific surface area. All of the samples exhibit monodispersed mesopore size distribution up to $150 \AA$. The specific surface area as high as $94 \mathrm{~m}^{2} / \mathrm{g}$ could be obtained with the addition of $5 \% \mathrm{AC}$ template and by a simple and inexpensive sol-gel method.

The optical bandgap of $\mathrm{TiO}_{2}$ nanoparticles has been determined from the absorption spectrum (Figure 10) using the following Tauc relation for a direct bandgap: $\alpha$ th $\nu=$ $A\left(h v-E_{g}\right)^{1 / 2}$, where $\alpha, t, v, A, E_{g}$, and $n$ are the absorption coefficient, the thickness of the sample, frequency of the light, a constant, and the bandgap energy, respectively.
The average bandgap was then estimated from the intercept of linear portion of $(\alpha t h v)^{2}$ versus $h v$, as shown in Figure 7 [9]. From the figure, the bandgap energy of $\mathrm{TiO}_{2}$ prepared using activated carbon in the amount of $0 \%, 5 \%$, and $10 \%$ by weight was $3.58,3.48$, and $3.59 \mathrm{eV}$, respectively. Generally, the particle size of the $\mathrm{TiO}_{2}$ has the bandgap energy between 3.0 and $3.2 \mathrm{eV}$. The observed large bandgap could be due to the effect of restricted movement of electrons, called "electron confinement."

In this experiment, the efficiency of catalytic $\mathrm{TiO}_{2}$ was tested by using the reduction of potassium dichromate $\left(\mathrm{K}_{2} \mathrm{Cr}_{2} \mathrm{O}_{7}\right)$ as the model compound (Figure 11). The absorbance peaks of $\mathrm{K}_{2} \mathrm{Cr}_{2} \mathrm{O}_{7}$ are found at $273 \mathrm{~nm}$ and 

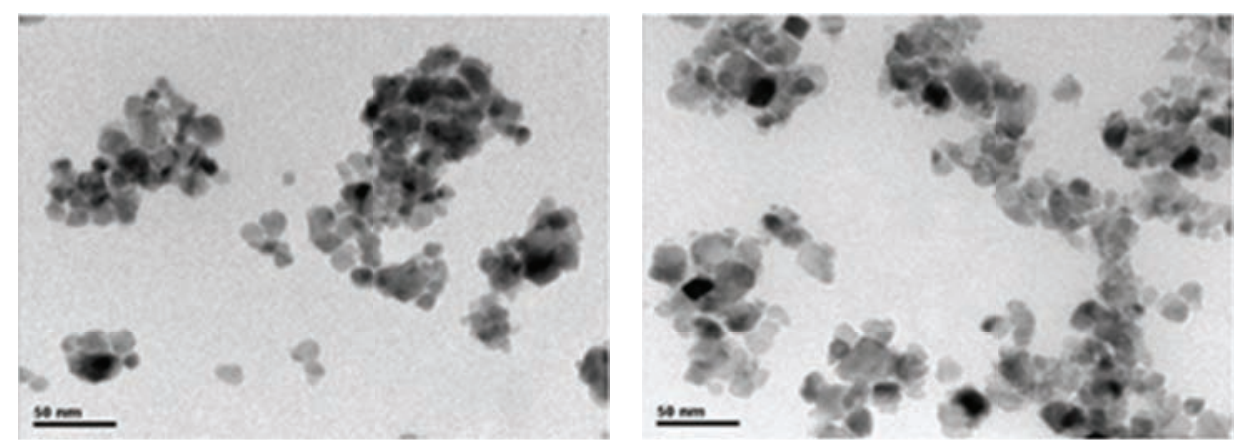

(a)
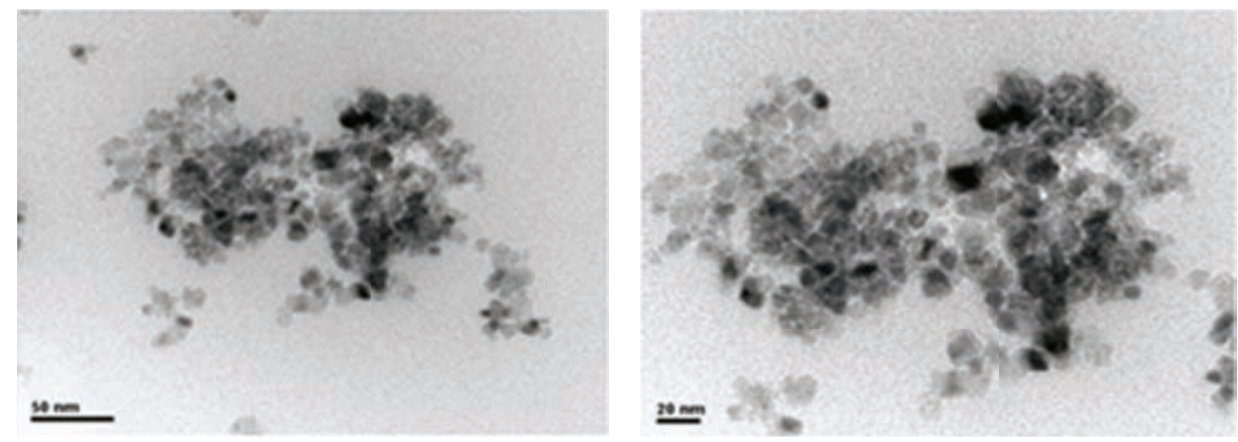

(b)
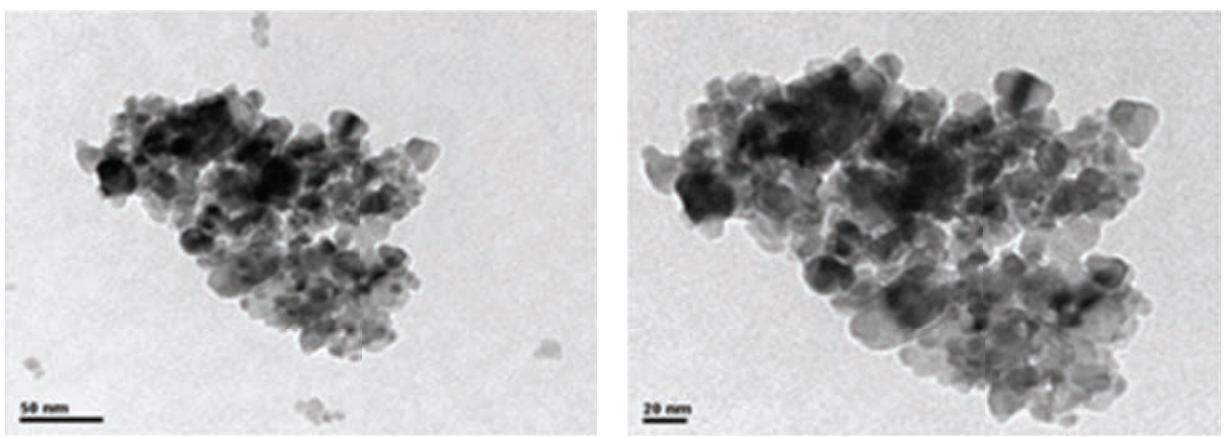

(c)

FIGURE 7: TEM images of synthesized $\mathrm{TiO}_{2}$ nanoparticles: (a) $0 \% \mathrm{AC}$, (b) $5 \% \mathrm{AC}$, and (c) $10 \% \mathrm{AC}$.

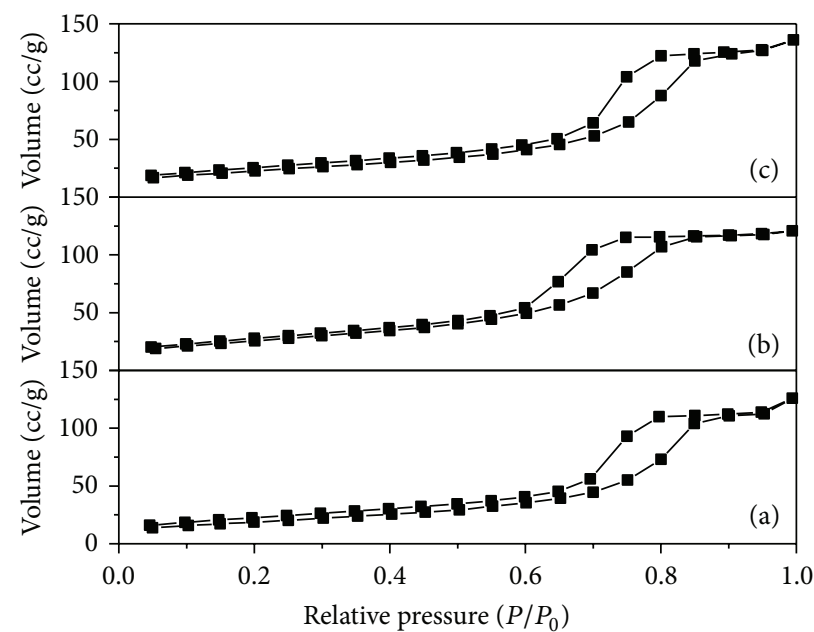

FIGURE 8: $\mathrm{N}_{2}$ adsorption/desorption isotherms of synthesized $\mathrm{TiO}_{2}$ nanoparticles: (a) $0 \% \mathrm{AC}$, (b) $5 \% \mathrm{AC}$, and (c) $10 \% \mathrm{AC}$. 


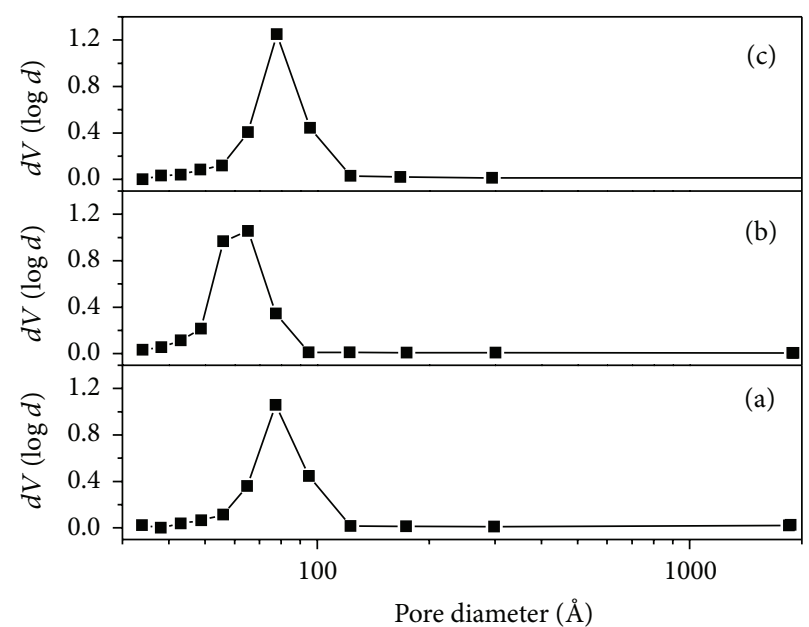

FIgURE 9: The BJH pore size distribution graphs of synthesized $\mathrm{TiO}_{2}$ nanoparticles: (a) $0 \% \mathrm{AC}$, (b) $5 \% \mathrm{AC}$, and (c) $10 \% \mathrm{AC}$.

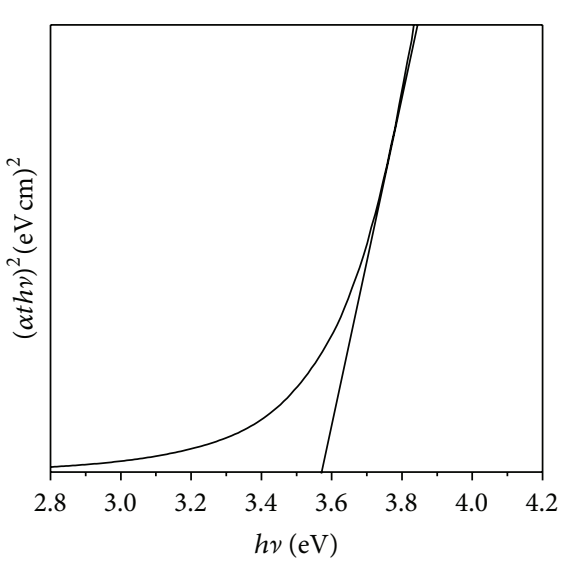

(a)

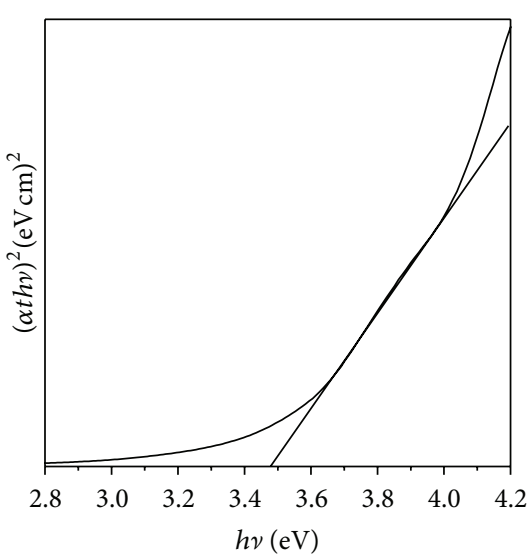

(b)

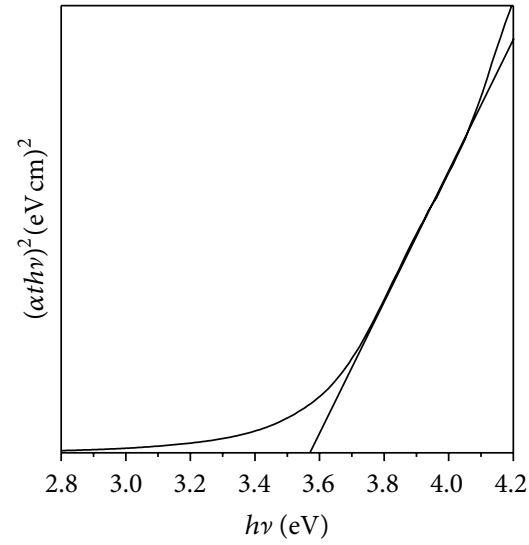

(c)

FIgURE 10: The relationship between $(\alpha t h v)^{2}$ and $h v$ of synthesized $\mathrm{TiO}_{2}$ nanoparticles: (a) $0 \% \mathrm{AC}$, (b) $5 \% \mathrm{AC}$, and (c) $10 \% \mathrm{AC}$.

$350 \mathrm{~nm}$. Without a photocatalyst, $\mathrm{K}_{2} \mathrm{Cr}_{2} \mathrm{O}_{7}$ is not degradable under the light irradiation using solar simulator (not shown here). With $\mathrm{TiO}_{2}$ as a photocatalyst, however, $\mathrm{TiO}_{2}$ can absorb photons with energy higher than its bandgap, causing electrons to jump across the bandgap into conduction band. These free electrons involved in the reactions with the $\mathrm{K}_{2} \mathrm{Cr}_{2} \mathrm{O}_{7}$ solution and $\mathrm{Cr}^{6+}$ could be reduced to $\mathrm{Cr}^{3+}$ in the form of $\mathrm{Cr}(\mathrm{OH})_{3}$, following the equations below $[10,11]$ :

$$
\begin{gathered}
\mathrm{TiO}_{2}+h \nu \longrightarrow \mathrm{TiO}_{2}\left(\mathrm{e}^{-}+\mathrm{h}^{+}\right) \\
\mathrm{H}_{2} \mathrm{CrO}_{4}+6 \mathrm{H}^{+}+3 \mathrm{e}^{-} \longrightarrow \mathrm{Cr}^{3+}+\mathrm{H}_{2} \mathrm{O} \\
\mathrm{HCrO}^{4-}+7 \mathrm{H}^{+}+3 \mathrm{e}^{-} \longrightarrow \mathrm{Cr}^{3+}+4 \mathrm{H}_{2} \mathrm{O} \\
\mathrm{Cr}_{2} \mathrm{O}_{7}^{2-}+14 \mathrm{H}^{+}+6 \mathrm{e}^{-} \longrightarrow 2 \mathrm{Cr}^{3+}+7 \mathrm{H}_{2} \mathrm{O} \\
\mathrm{CrO}_{4}{ }^{2-}+8 \mathrm{H}^{+}+3 \mathrm{e}^{-} \longrightarrow \mathrm{Cr}^{3+}+4 \mathrm{H}_{2} \mathrm{O}
\end{gathered}
$$

As a result, the absorbance intensity decreased over exposure time.

In addition, it is found that the maximum peaks were red-shifted toward longer wavelength. This could be due to the transformation from dichromate $\mathrm{K}_{2} \mathrm{Cr}_{2} \mathrm{O}_{7}$ into chromate $\mathrm{K}_{2} \mathrm{CrO}_{4}$ caused by hydroxyl groups on the surface of $\mathrm{TiO}_{2}$ nanoparticles, following the equation

$$
\mathrm{Cr}_{2} \mathrm{O}_{7}^{2-}+\mathrm{OH}^{-} \longrightarrow 2 \mathrm{CrO}_{4}^{2-}+\mathrm{H}^{+}
$$

With optical filter, a decrease in absorbance intensity of $\mathrm{K}_{2} \mathrm{Cr}_{2} \mathrm{O}_{7}$ aqueous solution is less than that without filter. This indicates that the reduction is less likely to take place due to less energy from the light to sufficiently excite electrons across the bandgap. Comparison of reduction capacities of synthesized $\mathrm{TiO}_{2}$ (10\% AC) with P25 Aeroxide $\mathrm{TiO}_{2}$, as shown in Figure 12, shows a higher photocatalytic activity. This suggests that the photocatalytic activity could be improved by changes in crystalline phase as well as specific surface area of photocatalytic materials.

\section{Conclusions}

$\mathrm{TiO}_{2}$ with controllable mesoporous anatase phase could be synthesized using sol-gel method and activated carbon 

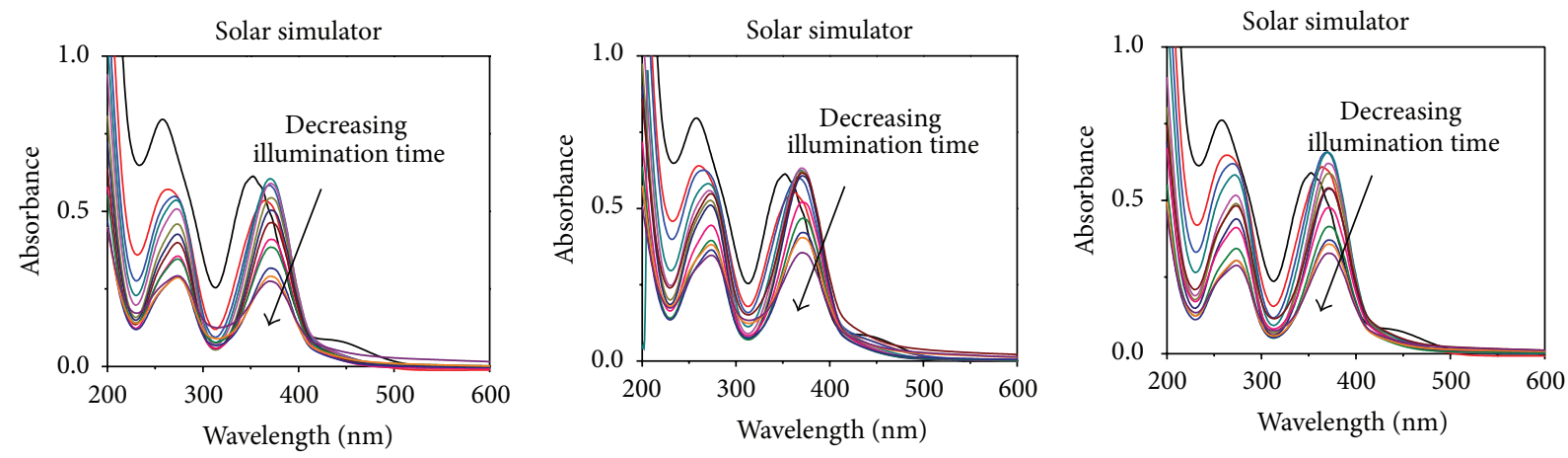

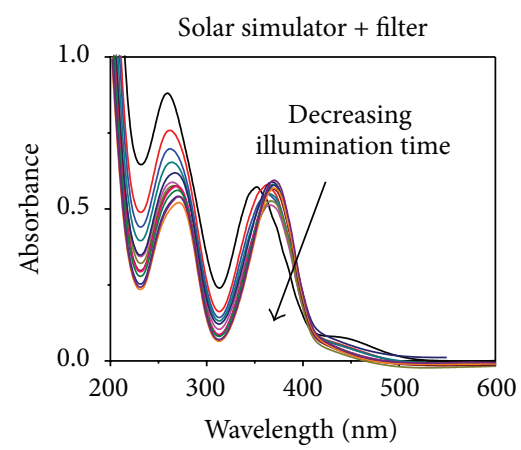

(a)

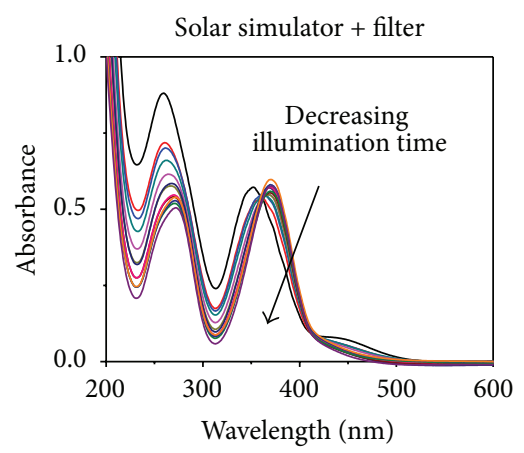

(b)

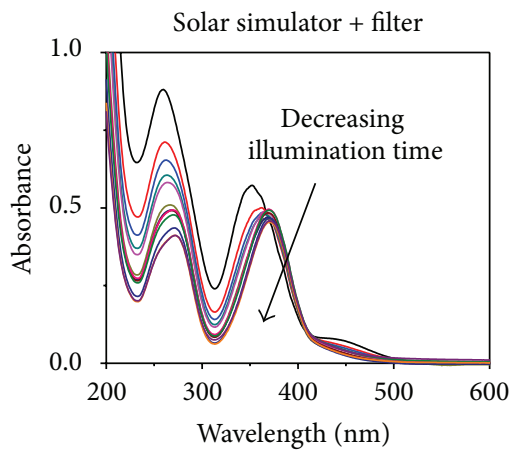

(c)

FIgURE 11: The absorbance spectrum of $\mathrm{K}_{2} \mathrm{Cr}_{2} \mathrm{O}_{7}$ aqueous solution with various $\mathrm{TiO}_{2}$ as photocatalysts as a function of illumination time: (a) $0 \% \mathrm{AC}$, (b) $5 \% \mathrm{AC}$, and (c) $10 \% \mathrm{AC}$. The solar simulator with xenon $150 \mathrm{~W}$ lamp with and without a filter was used as a light source.

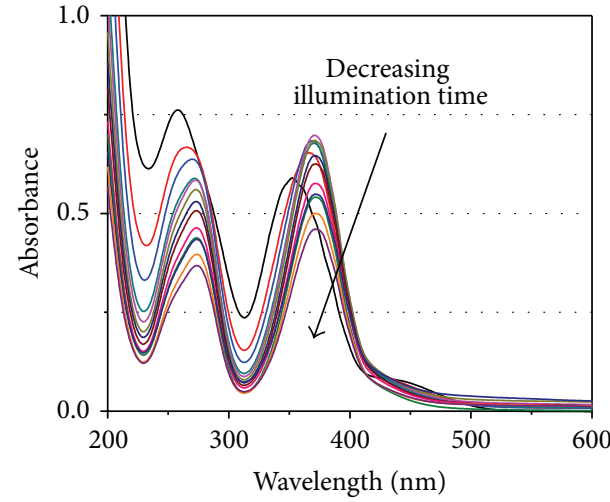

(a)

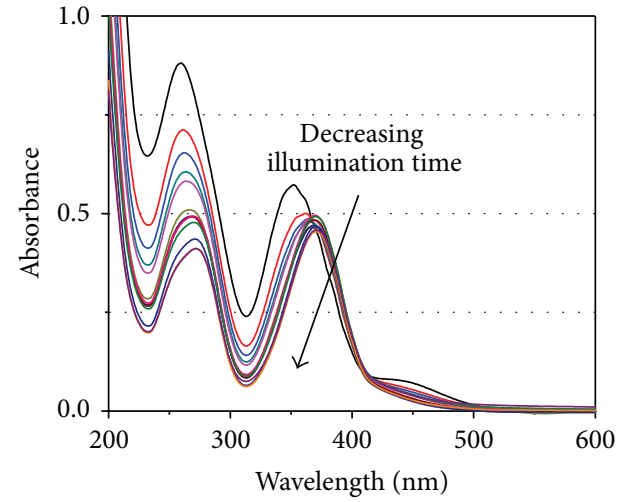

(b)

Figure 12: The absorbance spectrum of $\mathrm{K}_{2} \mathrm{Cr}_{2} \mathrm{O}_{7}$ aqueous solution with (a) $\mathrm{P} 25$ Aeroxide $\mathrm{TiO}_{2}$ and (b) $\mathrm{TiO}_{2}$ synthesized with $10 \%$ AC as photocatalysts as a function of illumination time. The solar simulator with xenon $150 \mathrm{~W}$ lamp with a filter was used as a light source.

template. The bandgap energy of synthesized $\mathrm{TiO}_{2}$ is 3.48$3.59 \mathrm{eV}$ due to the effect of electron confinement. The performance of $\mathrm{TiO}_{2}$ as a photocatalyst gave a good result when using lighting source system in the UV region. Over irradiation time, the concentration was decreased, indicating an increase in reduction of $\mathrm{Cr}^{6+}$. Furthermore, there was evidence that the two main absorption peaks were red-shifted to the right due to the transformation of dichromate $\mathrm{Cr}_{2} \mathrm{O}_{7}{ }^{2-}$ into chromate $\mathrm{CrO}_{4}{ }^{2-}$ form by hydroxyl group on $\mathrm{TiO}_{2}$ surface.

\section{Conflict of Interests}

The authors declare that there is no conflict of interests.

\section{Acknowledgments}

The authors wish to thank the Department of Materials Science and Engineering, Faculty of Engineering and Industrial Technology, Silpakorn University, and the National Center of Excellence for Petroleum, Petrochemicals and Advanced 
Materials for supporting and encouraging this investigation. This work was supported by the Higher Education Research Promotion (HERP), the Office of the Higher Education Commission.

\section{References}

[1] Y. C. Zhang, J. Li, M. Zhang, and D. D. Dionysiou, "Sizetunable hydrothermal synthesis of $\mathrm{SnS}_{2}$ nanocrystals with high performance in visible light-driven photocatalytic reduction of aqueous Cr(VI)," Environmental Science and Technology, vol. 45, no. 21, pp. 9324-9331, 2011.

[2] L. E. Eary and R. Dhanpat, "Chromate removal from aqueous wastes by reduction with ferrous ion," Environmental Science and Technology, vol. 22, no. 8, pp. 972-977, 1988.

[3] T. K. Yurik and A. K. Pikaev, "Radiolysis of weakly acidic and neutral aqueous solutions of hexavalent chromium ions," High Energy Chemistry, vol. 33, no. 4, pp. 208-212, 1999.

[4] M. Pal, J. G. Serrano, P. Santiago, and U. Pal, "Size-controlled synthesis of spherical $\mathrm{TiO}_{2}$ nanoparticles: morphology, crystallization, and phase transition," Journal of Physical Chemistry $C$, vol. 111, no. 1, pp. 96-102, 2007.

[5] G. Wang, "Hydrothermal synthesis and photocatalytic activity of nanocrystalline $\mathrm{TiO}_{2}$ powders in ethanol-water mixed solutions," Journal of Molecular Catalysis A, vol. 274, no. 1-2, pp. 185191, 2007.

[6] V. Loryuenyong, K. Angamnuaysiri, J. Sukcharoenpong, and A. Suwannasri, "Sol-gel template synthesis and photocatalytic behavior of anatase titania nanoparticles," ScienceAsia, vol. 38, pp. 301-306, 2012.

[7] V. Loryuenyong, A. Buasri, C. Srilachai, and H. Srimuang, "The synthesis of microporous and mesoporous titania with high specific surface area using sol-gel method and activated carbon templates," Materials Letters, vol. 87, pp. 47-50, 2012.

[8] J. B. Joo, I. Lee, M. Dahl, G. F. Moon, F. Zaera, and Y. Yin, “Controllable synthesis of mesoporous $\mathrm{TiO}_{2}$ hollow shells: toward an efficient photocatalyst," Advanced Functional Materials, vol. 23, no. 34, pp. 4246-4254, 2013.

[9] B. M. Weckhuysen and R. A. Schoonheydt, "Recent progress in diffuse reflectance spectroscopy of supported metal oxide catalysts," Catalysis Today, vol. 49, no. 4, pp. 441-451, 1999.

[10] S. Tuprakay and W. Liengcharernsit, "Lifetime and regeneration of immobilized titania for photocatalytic removal of aqueous hexavalent chromium," Journal of Hazardous Materials, vol. 124, no. 1-3, pp. 53-58, 2005.

[11] C. E. Barrera-Díaz, V. Lugo-Lugo, and B. Bilyeu, "A review of chemical, electrochemical and biological methods for aqueous Cr(VI) reduction," Journal of Hazardous Materials, vol. 223-224, pp. 1-12, 2012. 

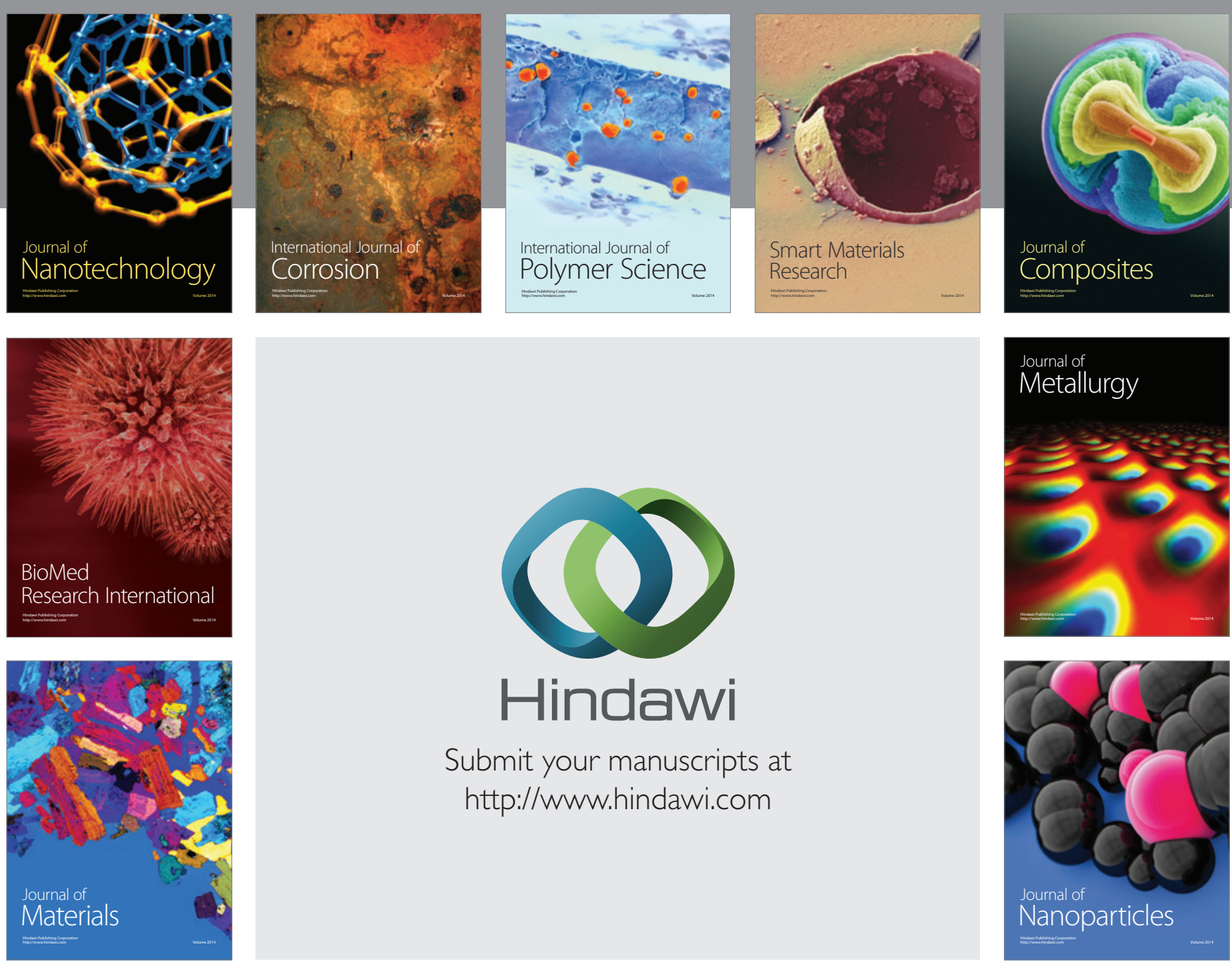

Submit your manuscripts at http://www.hindawi.com
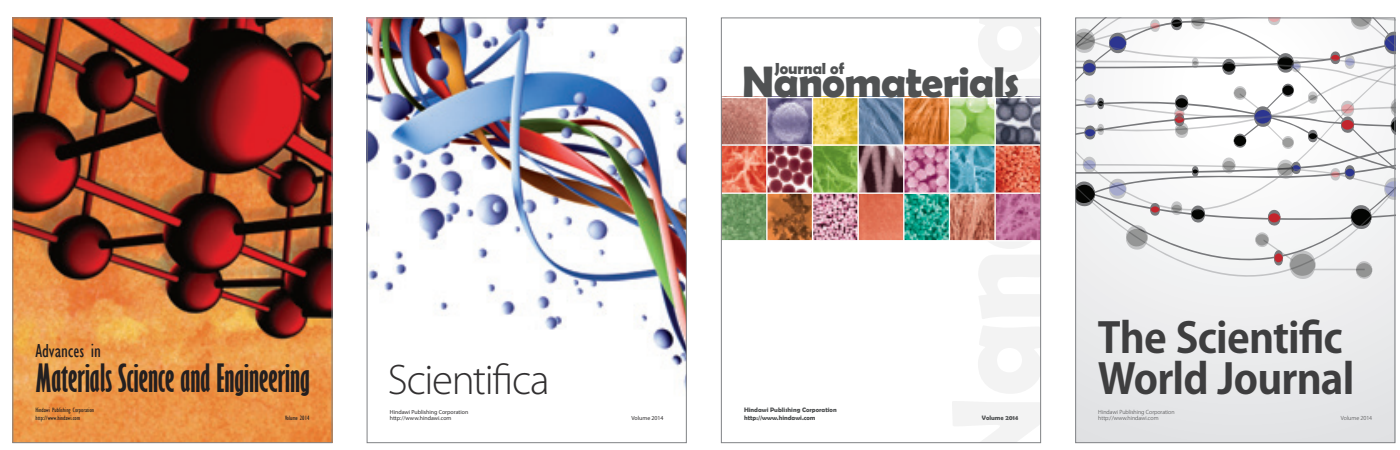

\section{The Scientific World Journal}
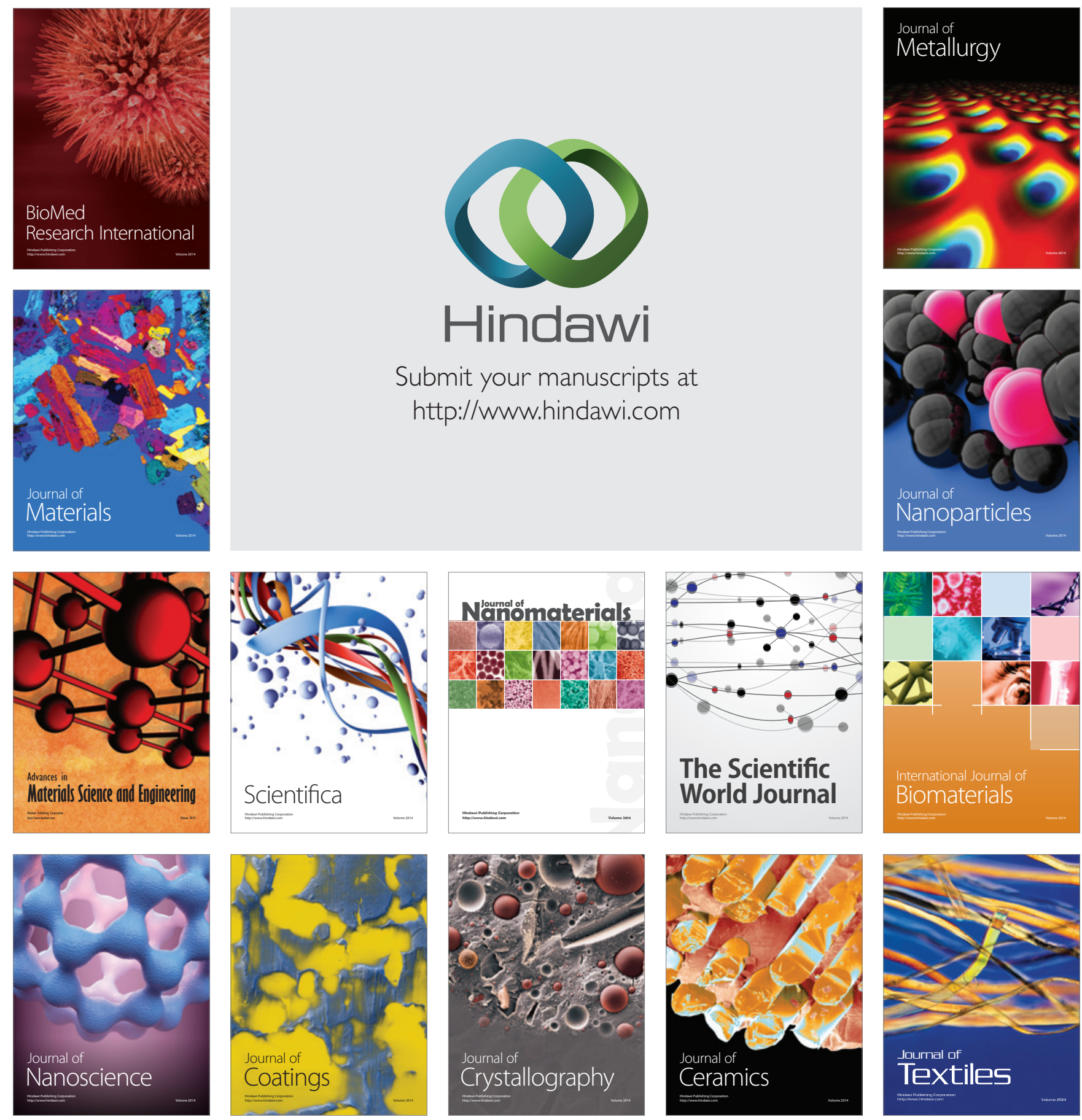